\title{
Treatment of Scaphoid Nonunions Using a Pronator Quadratus Pedicled Bone Graft
}

\author{
Mun Suk Jang ${ }^{1}$, Yu Seok Seo ${ }^{2}$ \\ ${ }^{1}$ Republic of Korea Air Force l8st Fighter Wing \\ Medical Center, Gangneung, Korea \\ ${ }^{2}$ Department of Orthopedic Surgery, \\ Soonchunhyang University Bucheon Hospital, \\ Soonchunhyang University College of \\ Medicine, Bucheon, Korea
}

Received: August 25, 2012

Revised: November 4, 2012

Accepted: November 19, 2012

Correspondence to: Mun Suk Jang

Republic of Korea Air Force 18st Fighter Wing Medical Center, 117 Wall Ho Pyong street

Hak dong, Gangneung 210-060, Korea

TEL: +82-33-649-3602

FAX: +82-33-645-8026

E-mail: jjangdol13@hanmail.net

This is an Open Access article distributed under the terms of the Creative Commons Attribution Non-Commercial License (http://creativecommons.org/ licenses/bync/3.0/) which permits unrestricted noncommercial use, distribution, and reproduction in any medium, provided the original work is properly cited.
Purpose: This study was to evaluate the clinical results of the treatment of scaphoid nonunions using a pronator quadratus pedicled bone graft.

Methods: Thirteen patients with a scaphoid nonunion were treated with pronator quadratus pedicled bone graft. The average age of the patients was 20.23 years (range: 19-22 years) and the minimum follow-up period was one year. In all patients, bone grafting was performed and screw was fixed by using a volar aspect of distal radius bone graft with pronator quadratus muscle.

Results: All 13 patients showed radiographic union with the average union time of 10.8 weeks (range: 9-13 weeks). Flexion, extension, radial deviation and ulnar deviation of wrist joint improved compared to the preoperative condition $(\mathrm{p}<0.05)$. Postoperative scapholunate and radiolunate angle improved compared to the preoperative condition $(\mathrm{p}<0.05)$. Eleven patients $(84.5 \%)$ showed excellent or good results according to Herbert and Fisher's score criteria of functional, subjective satisfaction and radiographic result.

Conclusion: Pronator quadratus pedicled bone grafting can be considered to be easily accessible technique on vascularized bone graft for osteosynthesis of scaphoid nonunions. It is proved to be effective for bone union, increased wrist joint motion.

Keywords: Scaphoid, Nonunion, Pronator quadrates pedicle bone graft

\section{서론}

주상골 골절은 수근골 골절 중 가장 빈도가 높은 골절로 ${ }^{1-3}$, 임상적 또는 방사선학적 간과로 인해 진단 및 치료가 지연되 어 불유합의 발생빈도가 5-10\% 정도 보고되고 있다 ${ }^{4,5}$. 스포츠 활동의 증가로 인해서 주상골 골절은 비교적 흔하게 발생하며 이에 따라 주상골 불유합 역시 흔하게 발생한다. 주상골 골절 의 불유합을 치료하지 않는 경우에는 장기적으로 수근관절의 불안정성 및 퇴행성 변화와 더불어 동통, 파악력 저하, 관절 강 직 등의 문제를 초래할 수 있어 적절한 치료가 중요하다.
불유합에 대한 수술적 치료방법으로 내재 골 이식(inlay bone graft), 개재형 골 이식(interpositional bone graft) 등 의 고전적인 골 이식술이 이용되고 있다 ${ }^{6}$. 최근에 들어서 근위 부 골절, 골절편의 무혈성 괴사 및 기존의 골 이식 실패 등 골 유합이 어려운 예에 대해 혈관화 골 이식을 이용한 치료법이 이용되고 있다. 그러나 혈관화 골 이식술은 술기가 어려워 경 험이 적은 술자가 시술하기는 쉽지 않다. 방형 회내근 유경 골 편 이식술은 1965년 Judent와 Rot-Camile ${ }^{7}$ 에 의해 시행된 후 비교적 쉬운 술기로 손목 주변의 불유합 및 무혈성 괴사에 서 혈관화 골 이식으로써 사용되고 있다. 그러나 국내에서는 


\section{J Korean Soc Surg Hand Vol. 17, No. 4, December 2012}

방형 회내근 유경 골편을 이용한 골 이식술에 대한 보고는 적 다. 이에 저자들은 주상골 불유합의 치료에 방형 회내근 유경 골편 이식술을 이용한 치료 결과를 분석 평가하였다.

\section{대상 및 방법}

\section{1. 수술 술기}

수술은 전 예에서 수장부 주상골 결절에서부터 원위부 요골 까지 절개를 가하여 주상골의 불유합 부위를 노출시켰다. 요 주상 유두골인대를 분리 후에 주상골 불유합 부위를 소파하 고, 딱딱한 부위를 절제하여 10-20 mm 정도의 타원형 상당 의 공간을 주상골 축을 따라 만들었다. 그리고 방형 회내근 유 경 골편 이식술을 하기 위해서 장무지 외전근이 붙는 원위부
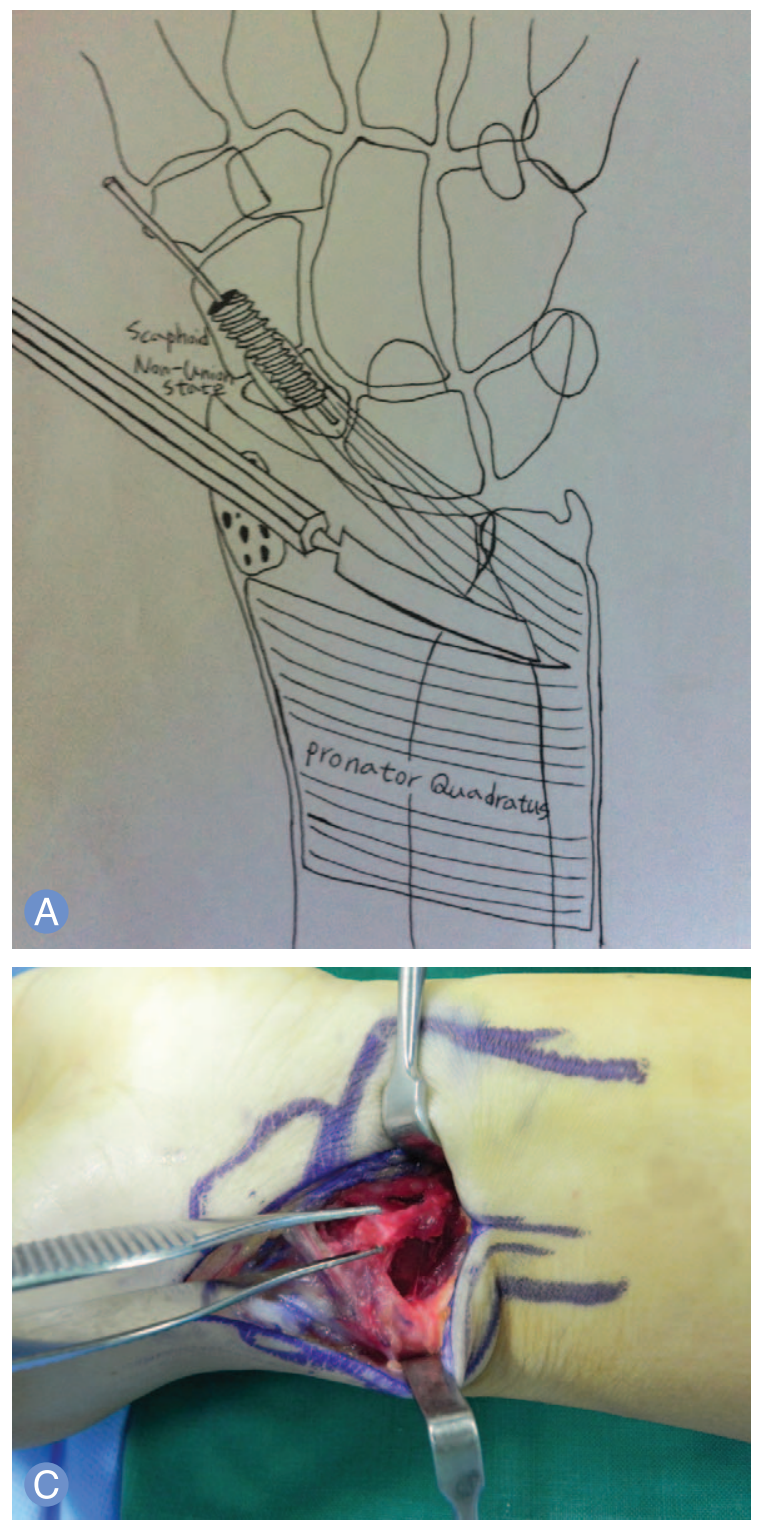

요골면에서 방형 회내근이 붙는 골편을 골절단기(osteotome) 을 통해서 분리하였다.

이때 골편에서 방형 회내근이 떨어지지 않도록 주의해야 한 다. 그리고 방형 회내근이 붙는 척골 부위를 골절단기를 통해 약화시켜(undermine), 주상골 불유합 부위까지 방형 회내근 의 유경 골편의 길이를 충분히 확보하고 장력이 가해지지 않 게 하였다. 원위부 요골 골편을 견인과 동시에 주상골의 타원 형공간에 골편을 삽입하였다(Fig. 1). 고정 시에는 원위 골편 에서 가이드 핀을 삽입하여 근위 골편으로 진행하는지 방향을 확인한 후 이식골을 넣고 전진시켰다. 그 후 골편을 원위부에 서 근위부로 Acutrack headless compression screw (Acumed, Hillsboro, OR, USA)를 이용하여 견고한 고정을 시행하였다 8.9 .

Fig. 1. (A) The pronator quadratus pedicled bone graft is obtained from styloid process of distal radius. Bone graft was inserted into the non-union site and fixed using Acutrack compression crew. (B, C, D) Intraoperative photographs show the surgical approach between the flexor carpi radialis and radial vessels, the graft after its detachment from the styloid process of the raidus and its insertion into the non-union site.
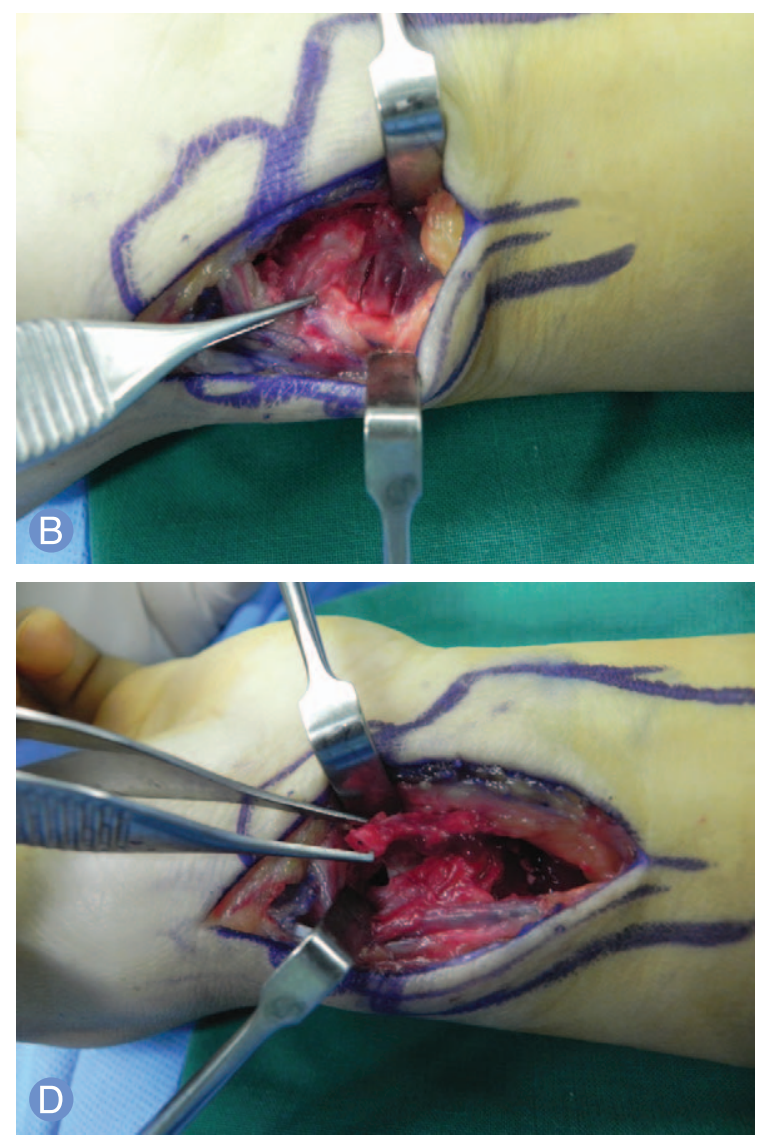


\section{2. 수술 후 관리}

수술 후 전 예에서 단 상지 무지 수상 석고 고정을 시행하였 으며 2주 간격으로 골유합 여부를 확인하기 위한 방사선 촬영 을 시행하였다. 방사선학적 골유합 소견이 확인되면 제거 가 능한 단 상지 부목으로 교체하고 완관절 운동 치료를 시작하 였고 부목은 4주간 더 착용하였다.

\section{3. 대상 및 방법}

단순 방사선에서 수근관절의 관절염이 동반되지 않는 주상 골 불유합 환자에 대해 2009년 4월부터 2011년 6월까지 본원 에서 방형 회내근 유경 골편 이식술을 시행받고 1년 이상 추시 가 가능한 군인 13 명을 대상으로 시행하였다. 연구 대상으로 는 주상골 불유합 환자중 곱사등 변형(humpback deformity) 이 없으면서 불유합면의 경화, 낭종, 골극 혹은 무혈성 괴사가 있는 경우를 택하였다. 환자의 성별은 모두 남자였으며, 평균 연령은 20.23세(범위: 19-22세), 손상 후 불유합 수술까지의 기간은 평균 10.84 개월(범위: 7-13개월)이었다. 손상 당시 주 상골 골절로 진단 후 석고 부목으로 치료받았으나 불유합이 발생한 경우가 5 예였으나, 8 예의 경우 초기에 주상골 골절로
진단받지 못하고 치료를 받지 않았다. 근위부 골절이 5 예가 있 었으며 그 중 3예에서 무혈성 괴사가 있었으며 원위부 골절이 8예가 있었다(Table 1).

방사선학적 평가는 완관절 후전면, 측면, 척측위 후전면, 측 면 사진촬영을 이용하였고, 골절 부위를 가로지르는 골소주가 두 개 이상의 촬영 사진에서 관찰될 때 방사선학적 골유합으 로 판정하였다. 최종 추시 때의 임상 결과는 환자의 주관적 및 기능적 만족도와 방사선학적 결과 항목을 점수화한 Herbert and Fisher 점수를 기준으로 평가하였다(Table 2) $)^{10}$. 그리고 수술 전후의 수근 관절의 운동범위와 주상-월상각과 요-월상 각을 평가하였다. 통계분석은 SPSS ver. 17.0 (SPSS Inc., Chicago, IL, USA)을 이용하여 비모순 검정 방법인 Wilcopxon-signed rank test를 시행하였으며 p값이 0.05 이하인 경우를 통계적으로 유의성이 있는 것으로 판정하였다.

\section{결과}

전 예에서 방사선학적으로 골유합을 확인할 수 있었으며, 수술 후 방사선학적 골유합까지의 평균 기간은 10.76 주(범위:

Table 1. Demographic data

\begin{tabular}{|c|c|c|c|c|c|c|c|}
\hline Patient & Age/sex & Cause of injury & $\begin{array}{l}\text { Duration of } \\
\text { injury (mo) }\end{array}$ & $\begin{array}{c}\text { Initial } \\
\text { treatment }\end{array}$ & $\begin{array}{c}\text { Time to } \\
\text { union (wk) }\end{array}$ & $\begin{array}{c}\text { Preoperative } \\
\text { X-ray }\end{array}$ & $\begin{array}{l}\text { Type of } \\
\text { nonunion }\end{array}$ \\
\hline 1 & $19 / \mathrm{M}$ & Sport injury & 7 & Cast & 11 & Middle third & Fibrous \\
\hline 3 & $21 / M$ & Sport injury & 10 & None & 9 & Proximal third & Scleortic \\
\hline 4 & $22 / M$ & Sport injury & 9 & Cast & 8 & AVN proximal third & Scleortic \\
\hline 5 & $19 / \mathrm{M}$ & Sport injury & 11 & None & 10 & AVN proximal third & Scleortic \\
\hline 7 & $20 / \mathrm{M}$ & Sport injury & 13 & None & 10 & Middle third & Fibrous \\
\hline 8 & $22 / \mathrm{M}$ & Sport injury & 12 & None & 11 & Proximal third & Fibrous \\
\hline 9 & $19 / \mathrm{M}$ & Sport injury & 13 & Cast & 9 & AVN proximal third & Fibrous \\
\hline 10 & $19 / \mathrm{M}$ & Sport injury & 9 & None & 11 & Middle third & Scleortic \\
\hline 11 & $20 / M$ & Sport injury & 10 & None & 12 & Middle third & Scleortic \\
\hline
\end{tabular}

AVN: avascular necrosis.

Table 2. Herbert and Fisher's score

\begin{tabular}{|c|c|c|c|c|}
\hline Result & Grade & Patient satisfaction & Clinical result & Radiographic result \\
\hline Excellent & 0 & Very happy asymptomatic & Normal function unrestricted use & Sound union no deformity \\
\hline Good & 1 & Improved minimal symptoms & $\begin{array}{l}\text { Minimal loss of function } \\
\text { unrestricted use }\end{array}$ & Apparent union minimal deformity \\
\hline Fair & 2 & Unchanged moderate symptoms & $\begin{array}{l}\text { Some restriction marked loss } \\
\text { of function }\end{array}$ & Doubtful union marked deformity \\
\hline Poor & 3 & Worse symptoms & $\begin{array}{l}\text { Marked loss of function restricted } \\
\text { use }\end{array}$ & Non union loosening of the fixation \\
\hline
\end{tabular}



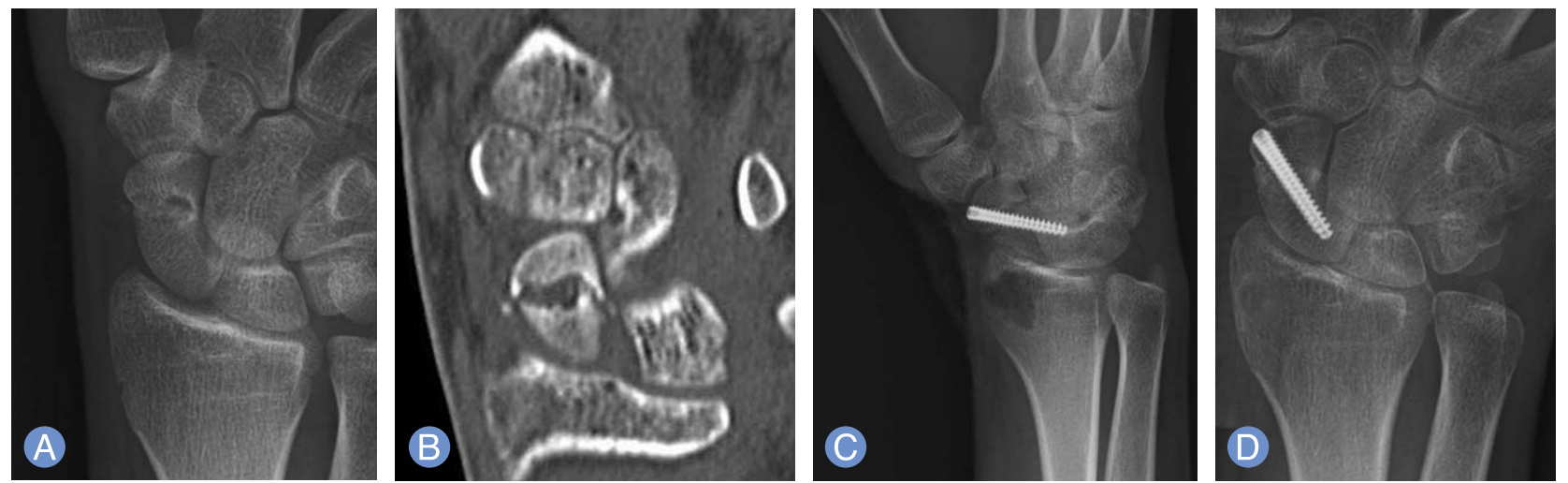

Fig. 2. A 21-year-old man underwent the osteosynthesis using pronator quadratus pedicled bone grafting. (A) Preoperative plain radiograph shows scaphoid waist non-union. (B) Preoperative computed tomography image shows sclerotic change of proximal fragment and osteophytes. (C) Postoperative X-ray. (D) At 9 weeks after operation, healing was achieved and clinical result was excellent.

Table 3. Comparison of postoperative and preoperative values

\begin{tabular}{lccc} 
Measurement & Preoperative & Postoperalive & p-value $(<0.05)$ \\
Flexion & 52.3 & 58.76 & 0.0 \\
Extension & 53.76 & 59 & 0.0 \\
Radial-deviation & 9.76 & 13 & 0.0 \\
Ulnar deviation & 26.7 & 33.9 & 0.0 \\
Scapho-lunate angle & 63 & 56 & 0.0 \\
Radio-lunate angle & 4.9 & 1.2 & 0.0 \\
\hline
\end{tabular}

9-16주)였다(Fig. 2). 수근 관절의 굴곡, 신전, 요측 변위 및 척측 변위의 운동범위가 수술 전 평균 $52.3^{\circ}, 53.8^{\circ}, 9.76^{\circ}$, $26.7^{\circ}$ 에서 최종 추시에 평균 $58.8^{\circ}, 59.0^{\circ}, 13.0^{\circ}, 33.9^{\circ}$ 로 측정되어서 수술 전후에 유의하게 증가하였다 $(\mathrm{p}<0.05)$

(Table 3).

영상의학적 변화로는 주상-월상각과 요-월상각은 수술 전 평균 $63.0^{\circ}$, 평균 후방 신전 $4.9^{\circ}$ 에서 수술 후 $56.0^{\circ}$ 와 후방 $1.2^{\circ}$ 로 수술전과 수술 후에 유의하게 향상되었다 $(\mathrm{p}<0.05)$ (Table 3). 수술 전후에서 후방 개재 불안정성을 보였던 예는 없었다.

Herbert and Fisher 점수를 기준으로 평가한 기능적 및 주 관적 만족도에서 13 예 중 8 예에서 매우 우수, 3 예에서 우수, 2 예에서 양호로 나타났다(Table 4). 수술 중에 주상골의 불유합 상태는 7예에서 경화성 상태였으며, 6 예는 섬유화된 상태로 관찰되었다.

\section{고찰}

저자들이 시행한 주상골 불유합에 대한 방형 회내근의 유경 골편 이식술은 골 유합 및 손목관절의 운동성 향상이 나타났 다. 주상골 불유합이 나타나는 주된 원인으로는 부적절한 치
Table 4. The 0verall results of pronator quadrates pedicle bone graft of non-uinon scaphoid fracture (Herbert and Fisher's score)

\begin{tabular}{lcc} 
Result & Non-union scaphoid fracture & Percentage (\%) \\
Excellent & 4 & 30.7 \\
Good & 7 & 53.8 \\
Fair & 2 & 15.4 \\
Poor & 0 & 0 \\
Total & 13 & 100 \\
\hline
\end{tabular}

료, 진단의 지연, 골절의 부위나 방향, 골편의 전위와 수근 불 안정 등이 있다 ${ }^{11,12}$. 치료받지 않는 주상골 골절은 시간이 지남 에 따라 퇴행성 변화가 진행하는데 주상골에만 국한되지 않고 요주상골을 침범하고 수근 관절 전체에 퇴행성 변화가 나타나 주상골 불유합 진행성 붕괴로 이른다 ${ }^{13}$. 특히 근위 골절의 경우 혈류장애로 인한 근위 골절편의 무혈성 괴사 가능성이 높고 근위 골절편이 작아서 견고한 고정이 힘들어 불유합의 확률이 높다 ${ }^{14}$.

주상골 불유합의 치료 방법으로 다양한 골 이식 방법이 소 개되었다. 1937년 Matti에 의해 보고된 내재골 이식 방법은 $\mathrm{Russe}^{6}$ 에 의해 피질망상 지주 골 이식술으로 변형되어 가장 보편화 되어 있고 70-90\% 정도의 유합률을 보고하고 있다. 그러나 근위 골편의 무혈성 괴사가 존재할 경우나 기존의 골 
이식 방법이 실패한 경우 고식적인 골 이식술 후의 유합률은 낮은 것으로 알려져 있다 $15-17$.

이러한 단점을 극복하기 위한 방법으로 주상골 불유합에 대 한 유경 골편 이식술을 시행하였다. 유경 골편 이식술에는 원 위 대퇴골이나 장골로부터 유리 혈관화 골 이식술을 하는 방 법, 주상골 주위에서 도서형 피판(islandflap)의 형태로 시행 하는 이식술 등 여러 방법들이 소개되었다, $8,1,13,17,18$. 이 중 가장 보편화되어 있는 방법이 원위 요골 부위에서 1,2 구획 간 상지 대 동맥을 혈관경으로 하는 이식골을 이용하는 것이다.

그러나 혈관화 골 이식술은 경험이 적은 술자에게 있어서는 시도하기가 쉽지 않고 술기가 어렵다. 또한 혈관경을 다치지 않게 유지하면서 정확하게 골절을 정복한 채로 삽입하고 고정 하기가 어려우며, 곱사등 변형(humpback deformity) 및 후 방 개재 분절 불안정을 동반한 주상골 불유합 의 경우 동반된 문제점을 교정하기가 어렵다 ${ }^{17}$. 그래서 시행한 방형 회내근 유 경 골편 이식술은, Kawai와 Yamamoto ${ }^{19}$ 가 주상골 불유합에 대해 처음으로 환자 8명을 대상으로 시행한 결과 골 유합 및 손목관절 운동성 증진 그리고 통증 호전을 보고하였다. 최근 에 Noaman 등 20 은 45 명을 대상으로 수장측 방형 회내근 유경 골편 이식술을 시행한 결과 Herbert and Fisher' s score상 $91.5 \%$ 에서 우수 이상의 결과가 나타났으며, 손목관절의 운동 성이 굴곡-신전에서 $10 \%$, 요골-척골에서 $15 \%$ 의 향상이 나타 났다. 또한 방형 회내근 유경 골편 이식술은 원위요골 골절 수 술적 치료방법과 유사하게 절개를 시행하기 때문에 쉽게 접근 이 가능하고 상처부위를 최소화 할 수 있다. 그리고 주상골 부 위의 혈류를 보존할 수 있으며, 손목관절의 굴곡과 신전의 소 실을 최소화 시킬 수 있다. 특히 전방 접근법을 통한 수술 방 법은 후방 개재성 불안정성이 있을 경우 교정할 수 있어 수술 후 손목관절의 운동성을 향상 시킬 수 있다 ${ }^{19,20}$.

그리고 방형 회내근 유경 골편 이식술을 시행할 경우 골 유 합까지의 기간에 대해 저자는 약 11 주를 보고하였다. 이 밖에 도 유경 골편 이식술을 시행한 $\mathrm{Park}^{18}$ 은 11 주, Doi 등흔 평균 12 주, Malizos 등 21 은 6-12주를 보고하였다. 반면에 기존의 골 이식 방법을 사용한 경우, Stark 등22은 평균 17 주를 보고 하였다.

유경골편 이식술의 내고정의 방법으로는 $\mathrm{K}$-강선, Herbert 나사 그리고 Acutrack 나사 등이 널리 이용되고 있고, 생흡수 성 나사못을 이용한 방법도 좋은 결과를 얻고 있다. 본 연구 증례들은 불유합 부위에 대하여 Acutrack 나사를 이용하여 고정하는 술식을 시행하였다. 근위부 골편이 너무 작거나 균 열되어서 골절편 골절이 될 가능성을 제외하면, 금속나사의 고정은 골절부를 압박하여 유합을 촉진시키고 견고한 고정으
로 수술 후 조기의 관절운동을 가능하게 한다. 이처럼 유경 골편 이식후 금속나사로 고정한 술식은 유합기간이 짧아 조기 의 관절운동이 가능하여 수술 후 재활 및 일상생활의 복귀에 긍정적인 영향을 줄 것으로 생각된다.

그러나 방형 회내근 유경 골편 이식술은 방형 회내근이 짧 은 경우, 골의 피질의 두께가 얇아 이식골 채취에 용이하지 않 는 단점을 가지고 있다. 또한 중간부 또는 원위부 주상골 불유 합에 대해서는 고전적인 골 이식술로 높은 골유합 성공률과 좋은 임상 결과가 나타나서 기술적으로 어려운 유경 골편 이 식술이 꼭 필요하다고는 할 수 없다.

결과적으로 본 연구에서는 방형 회내근 유경 골편 이식술을 근위 골편의 무혈성 괴사를 포함한 주상골 불유합 13 예에 대 해서 시행결과 높은 유합률과 짧은 유합 기간을 보였다. 또한 손목관절의 운동성이 굴곡-신전 및 요골-척골 모두에서 향상 되었으며, 손목관절의 주상-월상각과 요-월상각이 의미 있게 교정되었다. 또한 Herbert and Fisher 점수상 2예를 제외하 고 우수 이상의 높은 점수가 나타났다.

그러나 본 연구의 제한점으로는 방형 회내근 유경 골편 이 식술을 시행한 환자 표본수가 적고 수술을 시행받은 환자들의 수술 전 상태가 모두 근위부 무혈성 괴사가 있지 않았으며, 군 인이라는 젊고 건강한 환자를 대상만으로 시행하였다는 것이 다. 또한 방형 회내근의 유경 골편의 길이에 따른 혈류 공급에 미치는 영향을 직접적으로 비교 연구할 수가 없어서 향후 충 분한 증례분석이 필요하다.

\section{결 론}

주상골 불유합이 진단되었을 때, 원위 요골의 방형 회내근 유경 골편이 식술은 단일 절개에 따른 상처의 최소화 및 유경 골편 이식술에 좀 더 손 쉽게 접근할 수 있다. 골 유합 및 손목 관절의 운동성 향상을 가져올 수 있는 효과적인 수술 기법이 라고 생각된다.

\section{참고문헌}

1. Cooney WP 3rd, Dobyns JH, Linscheid RL. Nonunion of the scaphoid: analysis of the results from bone grafting. J Hand Surg Am. 1980;5:343-54.

2. Cooney WP, Linscheid RL, Dobyns JH, Wood MB. Scaphoid nonunion: role of anterior interpositional bone grafts. J Hand Surg Am. 1988;13:635-50.

3. Gelberman RH, Wolock BS, Siegel DB. Fractures and 
non-unions of the carpal scaphoid. J Bone Joint Surg Am. 1989;71:1560-5.

4. Proctor MT. Non-union of the scaphoid: early and late management. Injury. 1994;25:15-20.

5. Tomaino MM, King J, Pizillo M. Correction of lunate malalignment when bone grafting scaphoid nonunion with humpback deformity: rationale and results of a technique revisited. J Hand Surg Am. 2000;25:322-9.

6. Russe O. Fracture of the carpal navicular. Diagnosis, non-operative treatment, and operative treatment. J Bone Joint Surg Am. 1960;42:759-68.

7. Judet R, Rot-Camille R. Fractures et pseudarthroses du scaphoide carpien. Utilisation d'un greffon pedicule. Actua Chir Orthop. 1965;4:196-214.

8. Lee JY, Sohn HM, You JW, Kim DH, Kim DY. Treatment of nonunion of proximal scaphoid fractures using vascularized bone graft. J Korean Orthop Assoc. 2005; 40:471-6.

9. Robbins RR, Ridge O, Carter PR. Iliac crest bone grafting and Herbert screw fixation of nonunions of the scaphoid with avascular proximal poles. J Hand Surg Am. 1995;20:818-31.

10. Herbert TJ, Fisher WE. Management of the fractured scaphoid using a new bone screw. J Bone Joint Surg Br. 1984;66:114-23.

11. Leslie IJ, Dickson RA. The fractured carpal scaphoid. Natural history and factors influencing outcome. J Bone Joint Surg Br. 1981;63-B:225-30.

12. Prosser GH, Isbister ES. The presentation of scaphoid non-union. Injury. 2003;34:65-7.

13. Cheon SJ, Cha SH, Kim HT. A comparative study of three different bone grafting methods for treatment of scaphoid nonunion. J Korean Orthop Assoc.
2010;45:179-87.

14. Ricardo M. The effect of ultrasound on the healing of muscle-pediculated bone graft in scaphoid non-union. Int Orthop. 2006;30:123-7.

15. Boyer MI, von Schroeder HP, Axelrod TS. Scaphoid nonunion with avascular necrosis of the proximal pole. Treatment with a vascularized bone graft from the dorsum of the distal radius. J Hand Surg Br. 1998;23:686-90.

16. Doi K, Oda T, Soo-Heong T, Nanda V. Free vascularized bone graft for nonunion of the scaphoid. J Hand Surg Am. 2000;25:507-19.

17. Park MJ, Lee JS, Shin SK. Treatment of scaphoid nonunionusing a pedicled vascularized bone graft. J Korean Orthop Assoc. 2006;41:871-6.

18. Park JW. Scaphoid fractures and nonunions: recent trends of treatment. J Korean Soc Surg Hand. 2011;16: 116-26.

19. Kawai H, Yamamoto K. Pronator quadratus pedicled bone graft for old scaphoid fractures. J Bone Joint Surg Br. 1988;70:829-31.

20. Noaman HH, Shiha AE, Ibrahim AK. Functional outcomes of nonunion scaphoid fracture treated by pronator quadratus pedicled bone graft. Ann Plast Surg. 2011; 66:47-52.

21. Malizos KN, Dailiana ZH, Kirou M, Vragalas V, Xenakis TA, Soucacos PN. Longstanding nonunions of scaphoid fractures with bone loss: successful reconstruction with vascularized bone grafts. J Hand Surg Br. 2001;26:330-4.

22. Stark HH, Rickard TA, Zemel NP, Ashworth CR. Treatment of ununited fractures of the scaphoid by iliac bone grafts and Kirschner-wire fixation. J Bone Joint Surg Am. 1988;70:982-91. 


\section{방형 회내근 유경 골편 이식술을 이용한 주상골 불유합의 치료}

\section{장문석 - 서유석}

'공군 18전투 비행단 항공의무대대, ${ }^{2}$ 순천향대학교부천병원 정형외과학교실

목적: 주상골 불유합을 방형 회내근 유경 골편 이식술을 이용하여 치료한 임상적인 결과를 평가하였다.

대상 및 방법: 주상골 불유합으로 방형 회내근 유경 골편 이식술을 시행받은 환자 13 명을 대상으로 하였다. 환자의 평균 연령은 20.23세(범위: 19-22세), 최소 추시 기간은 1년이었다. 모든 예에서 수장 측 원위 요골에서 방형 회내근을 이용하 여 유경 골편 이식술을 하고 나사로 고정술을 시행하였다.

결과: 모든 13명 환자에서 방사선학적으로 골 유합을 확인할 수 있는 평균 기간은 10.76주(범위: 9-13주)였다. 모든 예에 서 수근 관절의 굴곡, 신전, 요측 변위 및 척측 변위의 운동범위가 수술 전 보다 유의하게 향상되었다(p<0.05). 또한 수술 후 주상-월상각과 요-월상각도 수술 전보다 유의하게 향상되었다(p<0.05). Herbert and Fishers 점수를 기준으로 평가 한 기능적, 주관적인 만족도 그리고 방사선학적 결과에서 우수 이상이 13예(84.5\%)였다.

결론: 주상골 불유합의 치유를 위한 방형 회내근 유경 골편 이식술은 접근이 쉬운 혈관화 골 이식술로 골 유합 및 손목관 절의 운동성 향상을 가져올 수 있는 효과적인 수술 기법이라고 생각된다.

색인단어: 주상골, 불유합, 방형 회내근 유경 골편 이식술

접수일 2012년 8월 25일 수정일 2012년 11월 4일 게재확정일 2012년 11월 19일 교신저자 장문석 강원도 강릉시 학동 월호평길 117

공군 제18전투비행단, 제18전투비행단 항공의무대대

TEL 033-649-3602 FAX 033-645-8026

E-mail jjangdol13@hanmail.net 